bromine is easily expressed by the significant figures in the value 2.47 permicron. Spectra in the visible, ultra-violet and nearer vacuum ultra-violet regions are in the range 1-10 permicron. The unit is easy to visualize, for example, with reference to colloidal dimensions. Its relations to important energy units are simple and easily remembered : 1 permicron = $1.24 \mathrm{eV} .=28.6 \mathrm{kcal} . /$ mole.

It is worth noting that although spectra recorded on a grating instrument are approximately linear on a wave-length scale, those recorded with prism instruments are much more nearly linear in wave number. Brode ${ }^{1}$ has suggested $100 \mathrm{~cm}^{-1}$ as a unit of wave number, and has rather incongruously named it the ' $\mathrm{cm} .^{-3}$ '. It would seem that the permicron is preferable in both size and notation.

Department of Chemistry,

University of Western Australia. Nov. 3.

'Brode, W. R., in "Physical Methods in Chemical Analysis", 1 (edit. by'W. G.'Berl, Academic Press, New York, 1950).

\section{Effect of Swine Influenza Virus on a Sulphonphthalein Dye}

WHEN swine influenza virus (Shope) is inoculated into the allantoic cavity of 11-day eggs simultaneously with a dye of the sulphonphthalein group (thymol blue, bromphenol blue, bromcresol green, bromcresol purple, bromthymol blue, phenol red, cresol red, $0.3 \mathrm{ml}$. of a 1 per thousand solution), it is found after forty-eight hours that a notable decrease in the colour intensity of the allantoic fluid has occurred as compared with that of the allantoic fluid of eggs inoculated with dye alone. We also found that this change in intensity was much less when the dye was inoculated together with human influenza $A$. For this experiment we used a W.S. strain, which for years had been cultivated on eggs in this Institute. This is also true of the swine influenza strain used for the first experiment. There was but little difference in the hæmagglutination titres of these strains. With this colour reaction it is possible to differentiate between the two strains. We are as yet unable to explain the cause of the change in colour intensity. A quantity of the dye is discoloured or removed from the allantoic fluid. There is no change in the $p H$ of the allantoic fluid during the development of the virus.

Virus Department,

H. KUNST

Institute for Infectious Diseases,

University, Utrecht.

Oct. 3.

\section{Synergistic Action of DDT and BHC Combined Sprays}

DDT and BHC have so far been applied separately in malaria control programmes. In order to find out how these two insecticides will behave in a combined spray, experiments were carried out both in the laboratory and in the field. A combined spray containing $25 \mathrm{mgm}$. DDT and $5 \mathrm{mgm}$. (BHC) gamma isomer per square foot was compared with deposit of $50 \mathrm{mgm}$. of DDT or $10 \mathrm{mgm}$. of gamma isomer per sq. ft. applied separately. The results of tests carried out with houseflies and mosquitoes in the laboratory and in the field (in villages of the Gurgaon district, Punjab) have shown that in all cases the residual effect with suspensions was better than with emulsions or solutions, and that DDT-BHC in combination gave a longer residual effect (for two weeks or more) than DDT or BHC alone. The synergistic action of DDT and BHC in combined sprays was very obvious, as not only the combined sprays were effective for a longer period but were also more efficacious in keeping down the density of mosquito population in the villages.

Malaria Institute of India,
Delhi.

RajIndar Pat

Oct. 11

\section{The Term 'Eelworm-free Soil' in Plant Quarantine Regulations}

INTERNATIONAL plant quarantine regulations now frequently require that imported plant material should be free from soil and should be accompanied by a certificate that the material was grown in soil free (inter alia) from the potato root eelworm, Heterodera rostochiensis, or possibly from other cyst-forming species of the same genus.

For the granting of such a certificate it is desirable to take a cornposite soil sample, mix it thoroughly, and recover any cysts contained in a weighed subsample. At present, a sub-sample of $200 \mathrm{gm}$. is frequently used. The numbers of cysts in unit weights of mixed soil are distributed in the Poisson distribution, from tables of which it can be found that a soil of mean content 0.7 cysts per $200 \mathrm{gm}$. will give a zero count in $\mathbf{5 0}$ per cent of cases, and one of 3 cysts per $200 \mathrm{gm}$. will give a zero count in 5 per cent of cases, assuming perfect recovery and recognition of cysts.

Cysts occasionally occur at depths of 24 in. or more, but most are to be found in the top $8 \mathrm{in}$. of soil. This depth of soil represents about 1 million $\mathrm{kgm}$. per acre, so that there would be 5 million sub-samples of $200 \mathrm{gm}$. each per acre.

It would therefore follow that a certificate of freedom from eelworm cysts, based on such a method of sampling, need not mean what it states. With an eelworm cyst population of $\mathbf{3} \cdot \mathbf{5}$ million per acre in the top $8 \mathrm{in}$. of soil, there is an even chance of no cyst being present in a 200 -gm. sample. With a population as high as 15 million per acre, no cyst will be present in such a sample in five cases out of 100. So that "No cysts found" really means, "It is very unlikely that there are more than 15 million cysts per acre". No harm is done provided that all concerned realize that this is the meaning of "eelworm. free soil".

Lest it be thought that such population-levels are trivial, and are made to seem imposing merely by using a per-acre basis, it should be added that at the 10-fold multiplication-rate per potato crop found by Oostenbrink in Holland ${ }^{1}$, such infestations might be expected to give rise to symptoms of eelworm disease after two successive potato crops and to a crop failure after a third or fourth.

Rothamsted Experimental Station,

B. G. Pethers Oct. 24.

1 Oostenbrink, M., thesis, Wageningen (1950). 